\title{
Ler apagamentos: diálogos possíveis com obras de J. Corona
}

\author{
Ana Paula Pereira', Deison Fernando Frederico", Francieri Beatrice Sabel Wostehoff"l, Leandro \\ Gaertner $^{\text {IV }}$ e Vinicius da Rocha Barros ${ }^{\vee}$
}

Resumo: Neste texto é proposta uma reflexão crítica sobre a produção de apagamento de subjetividades no contexto da má gestão da crise relacionada à pandemia do coronavírus, em contraponto com as obras intituladas "pensar em não ler" e "livro espectro", ambas da artista Joana Corona. Inicialmente são apresentadas as obras e, em seguida, uma leitura analítica que permite trazer à tona a discussão do apagamento de vidas e da memória de vidas no contexto pandêmico.

Palavras-chave: Pandemia. Apagamento. Arte e Luto.

\section{To read erasures: possible dialogues with works by J. Corona}

\begin{abstract}
In this text a critical reflection about the production of subjectivity erasure in the context of the crisis related to the poor management of the coronavirus pandemic is proposed, in counterpoint with the works "think about not reading" and "spectrum-book", both from the artist Joana Corona. Initially the works are presented, followed by an analytical reading, which allows to bring the discussion about the erasure of lifes and the memory of lifes in the pandemic context.
\end{abstract}

Keywords: Pandemic. Erasure. Art and Mourning.

I Doutoranda em Psicologia Social e Cultura no PPGP/UFSC. Mestra em Psicologia Cognitiva no CFCH-UFPE. Graduada em Psicologia na FURB/SC. Discente da Universidade Federal de Santa Catarina, Trindade - Florianópolis/ SC, 88040-970. E-mail: app.theiss@gmail.com. ORCID: https://orcid.org/0000-0002-0823-1669. Lattes iD: http:// lattes.cnpq.br/5304386649611196 Florianópolis, Brasil.

II Mestre em Saúde Coletiva pelo ISC-UFF, Especialista em Saúde da Família e Comunidade pela UNIPLAC, graduado em Psicologia pela Universidade Regional de Blumenau. Docente do Centro Universitário IBMR, Av. das Américas, 2603 - Barra da Tijuca, Rio de Janeiro - RJ, 22631-002. E-mail: deisonf@hotmail.com; ORCID: https://orcid.org/00000001-8432-8369. Lattes iD http://lattes.cnpq.br/4994732681331019. São Paulo, Brasil.

III Psicóloga; aluna especial em Psicologia Social e Cultura no PPGP/UFSC. Graduada em Psicologia na FURB/ SC.Discente da Universidade Federal de Santa Catarina, Trindade - Florianópolis/SC, 88040-970. E-mail: fran.sabel@ gmai.com. ORCID: https://orcid.org/0000-0003-2191-0786. Lattes iD: http://lattes.cnpq.br/7645651066937982. Florianópolis, Brasil.

IV Doutor em Musicologia na Universidade Paris-Sorbonne (Paris IV). Mestre em Música no DEARTES-UFPR. Graduado em Flauta-Tranversal- EMBAP/UNESPAR. Professor colaborador da Universidade Federal do Paraná, 638 - Batel, Curitiba - PR, 80420-170. E-mail: legaertner@hotmail.com. ORCID: https://orcid.org/0000-0001-86066761. Lattes iD: http://lattes.cnpq.br/9249239765960476. Curitiba, Brasil.

V Psicanalista; mestrando em Psicologia Social e Cultura no PPGP/UFSC. Discente da Universidade Federal de Santa Catarina, Trindade - Florianópolis/SC, 88040-970. E-mail: viniciusrbarros@gmail.com. ORCID: http://orcid. org/0000-0002-8416-2722. Lattes iD: http://lattes.cnpq.br/7072208032680252. Florianópolis, Brasil. 
É evidente que a guerra afastará esse tratamento convencional da morte. Não é mais possível negar a morte; temos de crer nela. As pessoas morrem de fato, e não mais isoladamente, mas em grande número, às vezes dezenas de milhares num só dia. (Sigmund Freud, 1916, p. 233).

\section{Considerações iniciais...}

A artista paranaense Joana Corona montou no ano de 2013 uma exposição em que apresentava uma biblioteca incomum. Dentro dessa biblioteca, diferentes experimentações foram estabelecidas pela artista. Performances outras com o livro e a palavra como material de trabalho foram propostos. Como uma espécie de constelação heterogênea de vestígios, as obras de Rastros (2013) foram produzidas durante todo o ano de 2012, tratavamse de livros, objetos, fotografias, vídeos, instalações e uma coletânea de livros/encartes da exposição no formato de passaportes que trazia reflexões em poesia e prosa.

A investigação das obras da exposição Rastro perpassa múltiplas linguagens e têm os livros como matéria-prima possível para outras formas de experimentação de leitura e de relação com a palavra. Como artista visual, poeta e editora, ela jogava com a experiência de escrever e compor poesias para serem lidas e vistas. Joana não estava interessada na escrita ou na leitura como experiências convencionais.

Selecionamos duas obras dessa exposição, em específico "Pensar em não ler", que são duas fotografias da série "para leito de rio, o que me escapa"; e "livro-espectro" da série "para leito de rio, o que me escapa".

As obras aqui apresentadas: "pensar em não ler" e "livro-espectro", encontram-se no encarte de apresentação da exposição. Estas obras que tratam da experiência de mergulhar um livro em um rio são acompanhadas de duas perguntas colocadas pela própria artista, na sua investigação da experiência da leitura, como perda e de como a memória produz perdas: "Como ler a impossibilidade da leitura? Como ver um apagamento?".

\section{O afundamento de um livro como estratégia para ver um apagamento...}

Como ler a impossibilidade da leitura? Como ver um apagamento? As obras provocam possíveis ensaios de respostas que a própria artista dá através da experimentação poética, do fazer inventivo e da potência da transgressão. Ao colocar um livro para performatizar fora dos seus contextos usuais, como objeto de leitura e aquisição de informação, ela provoca impacto inevitável sobre o leitor. O que somos levados a ler/ver nessas duas sequências de 
Figura 1

Joana Corona Pensar em não ler, 2012. Duas fotografias da série Para leito de rio, o que me escapa, 2012
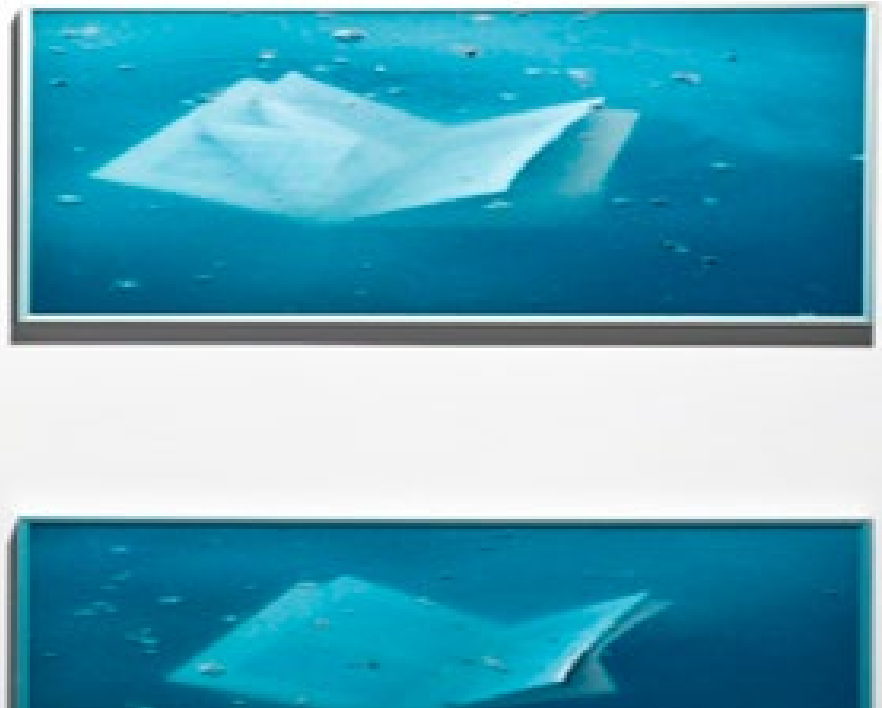

imagens, em que um livro é mergulhado, flutua e afunda? Antes da imersão plena o livro-espectraliza, e, assim como um fantasma, intocável, emerge. Quais outras interrogações colocam essas obras de Joana Corona? O que podemos considerar como pontos ou ângulos dos quais partimos para uma análise do que suscitam essas obras, seus títulos, suas perguntas e o que elas nos permitem problematizar em tempos pandêmicos?

Como artista visual, Joana Corona produziu uma obra que pode ser lida como poesia, em que ler e ver, problematizar e olhar pertencem a um único e mesmo instante. Para ler a impossibilidade da leitura, para que possamos ver um apagamento, a artista produz experimentações que partem de um gesto: o da retirada. Mergulha um livro no movimento de um rio, gesto que cria através da perda e do apagamento, uma forma de presença. Mais do que dar uma resposta, através do fazer performatizar de formas outras o livro, as obras propõem o desafio de lermos através da inacessibilidade ao texto, ler os indícios do que já não está, do que naufragou, possibilitando outra imagem, feita de rastros, de efêmeros, entre sombras, uma ausência-presente.

Numa primeira camada, pode-se trazer à discussão, mirando as imagens, os títulos das obras: "Pensar em não ler" e "livro-espectro". Pensar em não ler nos leva à impossibilidade da experiência de ler, faz-nos considerar a passagem do tempo, o que se apreende e o que se perde, o que dura e o que se apaga. 

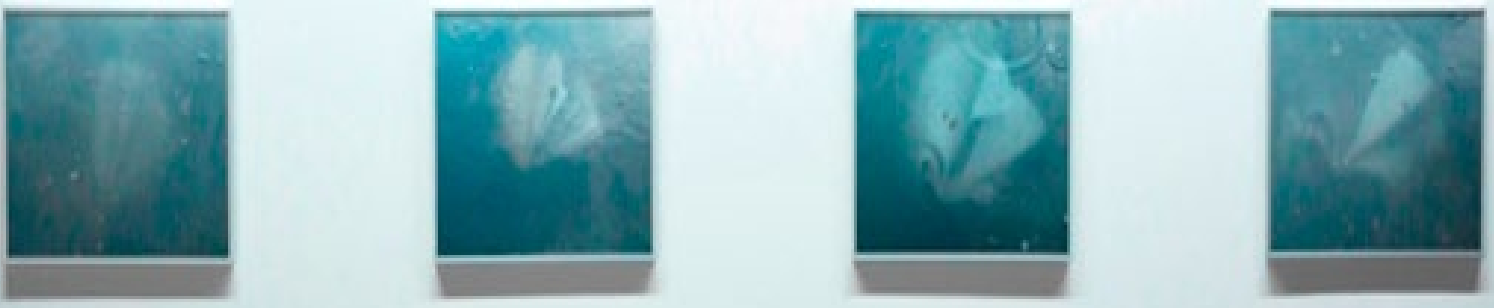

Figura 2

Joana Corona Quatro fotografias da série Para leito de rio, o que me escapa, 2012
A artista que oferece um livro a um rio e relaciona com as alteridades no plano da imanência, que é a própria expressão da vida em sua mais variada forma e multiplicidade. Livros podem ser vistos como objeto-lugares que guardam as palavras, que contam as histórias. Nas mãos de uma artista os livros protagonizam outros papéis e, como metáforas de si mesmos, recriam realidades outras no movimento de experimentar a relação do fluxo que há entre palavra e imagem, vendo palavra como imagem e lendo imagem como texto. As obras parecem trazer à tona certa fragilidade da palavra escrita ou do livro, como aquele objeto em que a palavra escrita produz apenas lembrança do tempo de vida das ideias de alguém.

Nas obras "Pensar em não ler" e "livro-espectro" a artista coloca em questão a própria condição do livro, seu suporte, seus sentidos múltiplos. Este objeto ao ser mergulhado no movimento de um rio, na fluidez da água, trata do vazio que a experiência de leitura produz e ao mesmo tempo_torna visível a fragilidade da escrita e do seu suporte como modo de deixar rastros.

Para Jeanne Marie Gagnebin (2002, p. 129),

[...] o rastro é fruto do acaso, da negligência, às vezes da violência, [...] o rastro deixado por um animal que corre ou por um ladrão que fugiu, ele denuncia uma presença ausente, quem deixou rastros não o fez com uma intenção de transmissão ou de significação, o decifrar dos rastros também é marcado por essa não-intencionalidade.

As obras "Pensar em não ler" e "livro-espectro" ao estarem conectadas sob o nome Rastros podem estar a nos dizer que estes rastros deixados pela artista são reflexões sobre os rastros que não se apagam. Ao mergulhar um livro, a artista propõe que nos deparemos com um apagamento. Propõe que nos deparemos com as perdas, e como as perdas são protagonistas de 
histórias, de ausências de histórias, de trabalhos da memória, daquilo sobre o que silenciou ou silenciamos. O mergulho de um livro, o seu afundamento, não deixa de ser uma escritura do silêncio. Esta experimentação dissolve a separação binária fundante da subjetividade entre memória e esquecimento, produzindo uma obra que trata da memória do esquecimento ou do esquecimento da memória, uma presença da ausência.

A obra "livro-espectro", especificamente, remete ao que não está mais e continua provocando presença. Embora esta obra esteja relacionada com a obra "pensar em não ler", o termo espectro nos leva à noção de fantasma, faz-nos considerar que, embora o fantasma seja espectral, e portanto, intocável e irreal, num sentido objetivo não se pode negar que ele ao mesmo tempo contém uma vasta dimensão de realidade em nossas subjetividades, assim como um fantasma. No sentido figurado, vivenciamos a presença de ausências, uma forma de estar do que já não é.

As obras "Pensar em não ler" e "livro-espectro" operam uma desconstrução do senso comum simbólico sobre a leitura e a escrita, sobre a forma usual de nos relacionarmos com o livro. A leitura e a escrita como experiência de aquisição e lembrança nos fazem pensar as relações entre o tempo, o esquecimento, e a memória como produtora de vazios. Os modos de manifestação dessas questões na imagem e na palavra, e mais precisamente, na intersecção entre a palavra/imagem na poesia e a palavra/imagem nas artes visuais estão em debate nas obras de Joana Corona. As obras perscrutam as zonas de contágio e mútua influência destes campos. O caráter sutil e efêmero e o aspecto matérico, encarnados no objeto livro, pleno de corporalidade e virtualidade, manifestam-se nesses trabalhos que indagam o esquecimento e a presença da ausência como uma produção da memória e de sua dinâmica escapante.

\section{Apagamento e Pandemia...}

O trabalho da artista é apresentado como um disparador e como alegoria para que possamos problematizar o que temos vivenciado das perdas em tempos pandêmicos. Como ver o apagamento provocado pela pandemia? Como ler a impossibilidade de ler o que afunda e aprofunda todos os dias? Como lidar com o espectro dos apagamentos?

No momento atual da pandemia todas, todos, todes conhecemos alguma pessoa que foi contaminado/a/e pelo coronavírus. Outros milhares de nós conhecem alguém que perdeu a vida ou que viveu a interrupção da vida de 
um ente querido devido a covid-19. Em algum momento, deparamo-nos com o medo de morrer, assim como de perder as pessoas que amamos. A pandemia colocou em nosso dia a dia a confrontação com os apagamentos, com aqueles(as) que nem ouvimos ou vemos desaparecer. Confrontounos com a imposição de outros hábitos e com privações das quais estamos tendo de ler e lidar. Não temos mais liberdade para circulação livre, já não nos encontramos e temos medo de abraçar e beijar. As crianças estão sem seus espaços de convívio entre seus pares. Nós adultos, entre diferentes circunstâncias, tivemos alterações na vida pessoal e profissional, com redução de trabalho e diminuição de renda. Perdemos lugares e fomos convocados à mudança. Essas transformações que o coronavírus, um vírus invisível ao olho nu, tem provocado, trazem com elas a chamada para um trabalho de luto. Importante ou não, cabe sublinhar que o luto está associado ao caráter do indecidível. Ou seja, não está nas mãos do domínio e da razão a decisão de ser afetado por ele, dada a sua dimensão espectral que reverbera nas afetações dos corpos.

Para Sigmund Freud o luto trata-se da "reação à perda de uma pessoa amada ou de uma abstração que ocupa seu lugar, como pátria, liberdade, um ideal, etc." (FREUD, 2011/1915, p. 47). A possibilidade de escrever questões que suscitam a pandemia, o contágio desenfreado e o aumento abismal de pessoas que têm suas vidas interrompidas pela covid-19, fazem parte de um trabalho de luto (FREUD, 2011/1915). No momento atual são 143.000 .000 mil pessoas, $143.000{ }^{1}$ histórias interrompidas, 143 mil histórias a serem elaboradas em seus apagamentos. Vamos chorar esses lutos? Somos seres constituídos por narrativas, temos um nome, temos um lugar de nascimento, uma filiação, um endereço, e falamos uma língua materna. Isso significa que somos seres que habitam o campo da linguagem. Somos as histórias que contamos, somos as histórias que contam sobre nós e não números a serem contabilizados (e subnotificados).

A possibilidade de narrar sustenta a vida no campo simbólico e essa razão dá às ações como os Inumeráveis (inumeraveis.com.br) ampla importância na empreitada coletiva de uma possibilidade de trabalho do luto. A criação de um espaço-memorial das vítimas do coronavírus no Brasil por Edson Pavoni tem o apoio de diversos colaboradores, e documenta com

1 Destacamos que este texto teve sua primeira versão produzida em outubro de 2020, desde então houveram revisões, dado o processo editorial. O número de mortes atuais da pandemia já mais que dobrou e segue com previsões pessimistas para os meses a seguir. 
identificação do nome completo, idade, cidade e uma pequena biografia de quem era aquela pessoa que teve sua vida perdida por um vírus e/ou pela desgovernança nacional. Nesse parágrafo, em memória de cada sujeito, evidencia-se a singularidade de uma vida aliançada com a sua comunidade.

Inumeráveis cumpre um papel vital enquanto monumento virtual. Até agora foram 611 postagens, cada uma narrando uma vida, uma despedida. O projeto Inumeráveis não dá conta de atualizar em postagens as mais de 143 mil vidas perdidas e tirá-las da condição fria de uma estatística que só aumenta. Contudo, cumpre um papel importante na possibilidade de realização de um trabalho de luto coletivo, afinal são 94,5 mil seguidores(as) desse perfil no Instagram (@inumeraveismemorial).

O luto é um trabalho doloroso, longo, às vezes infindável (dada à impossibilidade de velar os mortos por conta do risco de contágio), e produz seus efeitos, abate, torna o mundo externo menos interessante e o interno caótico. Não é por menos que temos escutado pessoas que relatam sentirem-se exaustas, sem energia, enlutadas e em constante estado de alerta, estafa física e mental. Nesse trabalho do luto, recai sobre cada um/ uma identificar quem ou o que perdeu, ainda que o que tenha sido perdido sejam rotinas ou coisas que aparentam ser de menor importância. O luto individual, íntimo e particular, não exclui as implicações de um trabalho de luto coletivo no qual as instituições públicas de saúde e de produção de conhecimento têm um papel fundamental contra o esquecimento e o silêncio, contra a indiferença com as mortes.

Ao trazermos o tema apagamento para este momento pandêmico, gostaríamos de relacioná-lo com a subnotificação de casos. Neste sentido, vemos ser ressaltada uma política de governo que se coloca como inquestionável, advinda de um chefe de Estado que se omitiu e se escondeu durante todo o processo eleitoral, por não aceitar ser confrontado e questionado, confundindo-se com o próprio Estado e se vendo como Total (absoluto, como a constituição).

O apagamento e a proposta de aniquilamento das diferenças e a destruição de toda produção anterior à covid-19 se dão e advêm através do desmonte das políticas públicas voltadas aos povos indígenas, à população LGBTQIA+, à população preta, às pessoas vivendo com vírus HIV, aos imigrantes, aos refugiados e outros grupos que se diferenciam dos padrões burgueses e hegemônicos.

A cultura não ficou de fora dos ataques e desmontes desse governo, com 
inúmeras trocas de gestores em sua pasta, na busca de alguém que sufocasse a expressão artística e que apontasse para as questões experienciadas socialmente, por via de perseguição, patrulhamento ideológico e não de financiamentos, tentando deturpar os registros que possam denunciar as faces mais perversas do autoritarismo dominante no cenário social.

Fazendo um paralelo entre as obras de Joana Corona e sua reflexão sobre o apagamento, lembramos aqui do ato de queimar livros, com o intuito de refazer ou desfazer uma história. Muitos regimes autoritários se utilizaram desta prática para desvelar o apagamento de culturas, de estórias e histórias e de marcas de povos, mas nunca sem deixar vestígios. Sendo o livro que afunda sob as águas ou que é consumido por labaredas, sua marca está registrada, sendo pelo que não foi possível ser dito, ou pelo que o ato explicitou. Mesmo que em nosso país não tenhamos fogueiras com livros ardendo, temos projetos de encarecê-los, para que se tornem inacessíveis à população e, portanto, deixem de existir no horizonte social mais amplo.

Ao não dar conta de normatizar o apagamento das histórias enterradas, vítimas, sobretudo, da falta de gestão da crise sanitária decorrente do coronavírus, o Ministério da Saúde cria mecanismos que dificultam a notificação e a publicização do número de óbitos, que foram potencializados por falta de gestão e políticas públicas eficientes e eficazes. Tal manobra também tira o Brasil do ranking da Organização Mundial da Saúde, forjando assim uma fuga das responsabilidades que são exigidas aos países que constituem essa organização. Certamente esse movimento não denuncia somente a falta de capacidade técnica dos gestores, mas como o país faz parte de um projeto de necropolítica, do extermínio de todas, todos e todes que não comungam desses ideais políticos. Em uma busca pelo apagamento das diferenças que se apresentam no viver coletivo, parecendo ser essa convivência insuportável para tal projeto político.

A doença covid-19, causada pelo coronavírus, denominado SARS-CoV-2, nos interpela e escancara em nossas caras, como máscaras, o tecido da fragilidade da crise ambiental do capitalismo. Escancara a fragilidade das estratégias e da política para redução do contágio e diminuição da velocidade das perdas, das sequelas, das histórias, das vidas. O que se lê é um Estado que transfere a responsabilidade da gestão pública nacional para as prefeituras, os comércios locais e os cidadãos.

Na pandemia encontramos um Brasil dito hospitaleiro, solidário, ordeiro, feliz e festivo. Porém, esta tentativa de colocar uma máscara nessa suposta identidade brasileira, esconde um país repleto de moral normativa e de 
violências. Violência vem do latim vis, força, e significa mais do que a rápida e restritiva associação com a delinquência e a criminalidade. Violência, para a filósofa Marilena Chauí (2011), é toda a forma de ação, pensamento ou sentimento que reduz outra pessoa à condição de uma coisa. Portanto, o outro não é visto como uma pessoa, mas como uma coisa que manipulo. Manipulo fatos, dados, estatísticas, produzo e sustento fake news para ampliar a cortina de fumaça e determinar como ponto final do debate o absoluto frente à fragilidade e a complexidade da vida humana. Ora, tanto a fragilidade quanto a complexidade não se reduzem a leituras únicas e universais. A defesa da cloroquina e da ivermectina é um exemplo triste e enfadonho, ou por que não, perverso, de tentar produzir sentido, ou melhor, produzir uma falsa segurança ou controle para a imersão - tal qual o livro da artista -, que estamos vivenciando e, em alguma medida, testemunhando.

\section{Considerações finais}

Importante reconhecer o lugar que a arte e, em alguma medida, a importância da criatividade e do humor como operadores disruptivos para essa longa tradição de produção de conhecimento e de produção de subjetividade que visa na ciência moderna, nas religiões e no jurídico uma adoção aos pressupostos da verdade universal e absoluta, que finda qualquer relação com as inquietudes geradas pela dúvida, pela fluidez ou pelo vazio.

O vazio não é meramente a ausência de materialidade ou concretude, tão pouco deve ser entendido como um buraco que precisa ser preenchido pelo cimento da razão e/ou pela demanda do consumo e até mesmo pelo divino. A inquietude conjuga com a sensação de vazio crônico que a complexidade humana cerceia, demandando representações (bens de consumo ou interpretações universalizantes, tutoriais) que apaziguem isso que nos é insabido e inquietante. Se a experiência humana é atravessada pelos incontáveis lutos a serem elaborados, seja por perdas pessoais (emprego, paixões, rotinas), seja pela perda de entes queridos ou pela solidariedade ao próximo, há de convir que a razão, a concretude e o absoluto necessitam de reflexões e problematizações que atestem sua falha com o simbólico e com o campo da linguagem.

A artista Joana Corona, que coincidentemente, partilha o sobrenome do vírus que nos altera e inquieta, ajuda-nos, através da sua expressão artística, a problematizar a dissolução da lógica binária das demais lógicas de opostos que solidificam a tradição das leituras que desconsideram 
qualquer outra possibilidade de ver/ler e tratar dos apagamentos. Com suas obras evidencia a força da arte enquanto estratégia, refúgio de vida, de continuidade, de produção de memória do que se perde e da fragilidade.

\section{Referências}

CHAUI, Marilena. Ética e Violência no Brasil. Revista Bioethikos, N. 5(4): 378-383, 2011.

CORONA, Joana. "Pensar em não ler" e "livro-espectro" 4 fotografias da série "para leito de rio, o que me escapa. Obras de arte que compuseram a exposição individual, Rastros, de Joana Corona.

CORONA, Joana. Rastros. Curitiba, Traço de uma sobra: sombra. PR: Ed. Da Casa, 2013.

FREUD, Sigmund. Luto e Melancolia. São Paulo: Cosac Naify, 2011.

FREUD, Sigmund. Escritos Sobre a Morte e a Guerra. Covilhã: Universidade da Beira Interior, 2009.

GAGNEBIN, Jeanne Marie. O rastro e a cicatriz: metáforas da memória. Pro-Posições, vol. 13, N. 3 (39) - set./dez. 2002. 